\title{
New prospectives in spinal anaesthesia for urogenital tract surgery in geriatric patients
}

\author{
Anna d'Elia, Francesca Grassia, Claudia Orabona, Maria Luisa Mingione, Lucia Marullo, Giuseppe Dimarzio, \\ Biagio Lettieri
}

From 26th National Congress of the Italian Society of Geriatric Surgery

Naples, Italy. 19-22 June 2013

\section{Introduction}

Spinal anaesthesia (SA) is the most commonly used anesthetic technique for transurethral resection of prostate (TURP) surgery in geriatric patient population [1]. Many geriatric patients have coexisting cardiac or pulmonary diseases, so it's very important to limit the distribution of the block to prevent the possible hemodynamic and pulmonary adverse effects. The purpose of this study is to compare the effectiveness of using intrathecal low dose bupivacaine-fentanyl combination with conventional dose prilocaine-fentanyl combination for day case TURP surgery in geriatric patient population [1]. We hypothesized that, using low dose bupivacaine-fentanyl combination provides shorter duration of block duration and postanesthesia care unit (PACU) stay with better hemodynamic stability than using conventional dose prilocaine-fentanyl combination.

\section{Methods}

Tacking as subjects 50 patients ASA II-III evaluation, 70 years of age or older with homogeneous co-morbidity, scheduled for elective TURP surgery without controindications for spinal anaesthesia we conducted the study. Patients' demographic data and surgery durations were comparable in groups. Patients were divided into 2 groups. Group $\mathrm{A}(\mathrm{n}=25)$ received $4 \mathrm{mg}$ bupivacine $0.5 \%+25 \mu \mathrm{g}$ fentanyl and Group $\mathrm{B}(\mathrm{n}=25)$ received $50 \mathrm{mg}$ prilocaine $2 \%$ $+25 \mu \mathrm{g}$ fentanyl intrathecal. This study has compared block quality and duration, postanesthesia care unit stay and adverse effects in two groups. Intraoperative monitoring consisted of heart rate, noninvasive blood pressure and oxygen saturation, which were recorded every 5 minutes. The highest dermatomal level of sensory block, the time

\footnotetext{
* Correspondence: biagio.lettieri@unina2.it
Dept. of Anesth. Surgical and Emergency Sciences-Intensive Care Unit - I

* Correspondence: biagio.lettieri@unina2.it
Dept. of Anesth. Surgical and Emergency Sciences-Intensive Care Unit - ॥ University of Naples, Italy
}

(C) 2013 d'Elia et al; licensee BioMed Central Ltd. This is an Open Access article distributed under the terms of the Creative Commons Attribution License (http://creativecommons.org/licenses/by/2.0), which permits unrestricted use, distribution, and reproduction in any medium, provided the original work is properly cited.

\section{Results}

Mean dermatomal level of highest sensorial block was higher in Group B(T8) than in Group A(T10). But the time to reach this highest sensorial block level were comparable in groups. Motor block at the time of reaching highest sensorial block in Group A was less than in Group B. Duration of block and PACU stay were significantly shorter in Group A (100.2 than in Group B(145,3. \pm 10.8$)$. Adverse effects during the procedure were shown (Table 1). In Group B, hypotension was seen in 4 patients and bradycardia was seen in 5 patients. Only one patient in Group A had hypotension and bradycardia. PONV(postoperative nausea and vomiting) was detected in one patient in Group A, and in six patients of Group B. These differences were significant between groups. None of the patients in either 
Table 1 Adverse effects in two groups

\begin{tabular}{lll}
\hline Adverse effects & Group $A(n=25)$ & Group $B(n=25)$ \\
\hline Bradycardia & 1 & 5 \\
\hline Hypotension & 1 & 4 \\
\hline PONV & 1 & 6 \\
\hline Block failure & 0 & 0 \\
\hline Pain during procedure & 0 & 0 \\
\hline
\end{tabular}

groups manifested block failure or pain during the procedure.

\section{Conclusions}

As known, systemic hypotension and bradycardia are the most common side effects during central neural blocks. Marked hypotension can be deleterious especially in geriatric patients with limited cardiac reserve $[2,3]$. High incidence of coronary disease in geriatric patients increases the risk of myocardial ischemia due to hypotension [2]. A high level of block is another important factor in the development of hypotension during SA [4]. Prilocaine was reported as such in day case surgeries with low incidence of transient neurological symptoms TNS. However, marked hypotension and bradycardia were reported in intrathecal prilocaine use. Bupivacaine has a low risk of TNS as well. Nonetheless, if used in conventional doses in day case surgeries, its main disadvantages are long duration of action and recovery and hemodynamic adverse effects like hypotension. Many different attempts have been attempted to decrease the block duration of bupivacaine, like lowering the dose and adding adjuvant drugs. Intrathecal opioids are known to enhance analgesia of subtherapeutic doses of local anesthetics. Thus, successful SA can be achieved by combining intrathecal opioids with low doses of local anesthetics that would be inadequate when used independently [2]. Using low doses of local anesthetics could shorten the block duration and its recovery and could also prevent the undesired hemodynamic adverse effects.

In conclusion, adequate SA can be provided by using $4 \mathrm{mg}$ bupivacaine and $25 \mu \mathrm{g}$ fentanyl combination with shorter block duration and PACU stay when compared with $50 \mathrm{mg}$ prilocaine and $25 \mu \mathrm{g}$ fentanyl combination for day case TURP surgeries. We also observed that a stable hemodynamic profile with low-dose bupivacaine becomes advantageous which is especially very important in geriatric patient population.

\section{Published: 16 September 2013}

\section{References}

1. Kararmaz A, Kaya S, Turhanoglu S, Ozyllmaz MA: Low dose bupivacainefentanyl spinal anesthesia for transurethral prostatectomy. Anaesthesia 2003, 58:526-530.
2. Kuusniemi KS, Pihlajamaki KK, Pitkanen MT, Helenius HY, Kirvela OA: The use of bupivacaine and fentanyl for spinal anesthesia for urologic surgery. Anesth Analg 2000, 91:1452-1456.

3. Rooke GA, Freund PR, Jacobson AF: Hemodynamic response and change in organ blood volume during spinal anesthesia in elderly men with cardiac disease. Anesth Analg 1997, 85:99-105.

4. Erdil F, Bulut S, Demirbilek S, Gedik E, Gulhas N, Ersoy MO: The effects of intrathecal levobupivacaine and bupivacaine in the elderly. Anaesthesia 2009, 64:942-946.

doi:10.1186/1471-2482-13-S1-A9

Cite this article as: d'Elia et al:: New prospectives in spinal anaesthesia for urogenital tract surgery in geriatric patients. BMC Surgery 2013 13(Suppl 1):A9
Submit your next manuscript to BioMed Central and take full advantage of:

- Convenient online submission

- Thorough peer review

- No space constraints or color figure charges

- Immediate publication on acceptance

- Inclusion in PubMed, CAS, Scopus and Google Scholar

- Research which is freely available for redistribution

Submit your manuscript at www.biomedcentral.com/submit 